\title{
Human embryonic stem cells display a pronounced sensitivity to the cyclin dependent kinase inhibitor Roscovitine
}

\author{
Guillermo A. Videla-Richardson ${ }^{\dagger}$, Verónica A. Furmento ${ }^{\dagger}$, Carolina P. Garcia, Olivia Morris-Hanon, \\ Gustavo E. Sevlever, Leonardo Romorini and María E. Scassa*
}

\begin{abstract}
Background: The essentially unlimited expansion potential and the pluripotency of human embryonic stem cells (hESCs) make them attractive for cell-based therapeutic purposes. Although hESCs can indefinitely proliferate in culture, unlike transformed cancer cells, they are endowed with a cell-intrinsic property termed mitochondrial priming that renders them highly sensitive to apoptotic stimuli. Thus, all attempts to broaden the insights into hESCs apoptosis may be helpful for establishing pro-survival strategies valuable for its in vitro culture and further use in clinical applications. Cyclin-dependent kinases (CDKs), a family of serine/threonine protein kinases originally identified as regulators of the eukaryotic cell cycle, can also regulate transcription and differentiation. Moreover, there are compelling data suggesting that its activities are involved in certain apoptotic programs in different cell types. Currently, it is not completely determined whether CDKs regulate apoptotic processes in rapidly proliferating and apoptosisprone hESCs. In this study, to elucidate the effect of CDKs inhibition in hESCs we used Roscovitine (ROSC), a purine analogue that selectively inhibits the activities of these kinases.

Results: Inhibition of CDKs by ROSC triggers programmed cell death in hESCs but not in proliferating somatic cells (human fibroblasts). The apoptotic process encompasses caspase- 9 and -3 activation followed by PARP cleavage. ROSC treatment also leads to p53 stabilization, which coincides with site-specific phosphorylation at serine 46 and decreased levels of Mdm2. Additionally, we observed a transcriptional induction of $p 53 A I P 1$, a repression of pro-survival factor Mcl1 and an up-regulation of pro-apoptotic BH3-only proteins NOXA and PUMA. Importantly, we found that the role of CDK2 inhibition appears to be at best accessory as an active CDK2 is not required to ensure hESCs survival.
\end{abstract}

Conclusion: Our experimental data reveal that hESCs, contrary to fibroblasts, exhibit a pronounced sensitivity to ROSC.

Keywords: Human embryonic stem cells, Roscovitine, Cyclin-dependent kinases, Apoptosis

\section{Background}

Human embryonic stem cells (hESCs) are pluripotent cells exceptionally dedicated to rapid unlimited proliferation [1]. At the pre-implantation stage of the blastocyst, as well as in vitro culture, hESCs repeatedly traverse the cell cycle and undergo successive symmetrical divisions to give rise to an equivalent progeny that exhibit identical self-renewal and differentiation properties. In comparison to

\footnotetext{
* Correspondence: mescassa@fleni.org.ar

${ }^{\dagger}$ Guillermo A. Videla-Richardson and Verónica A. Furmento contributed equally to this work.

Laboratorios de Investigación Aplicada en Neurociencias (LIAN-CONICET),

Fundación para la Lucha contra las Enfermedades Neurológicas de la

Infancia (FLENI), Belén de Escobar, Provincia de Buenos Aires, Argentina
}

proliferating somatic cells, hESCs show atypical cell cycle properties such as short doubling time (15-16h), truncated G1 phase (3-4h) and reduced or absent checkpoints $[2,3]$. Although hESCs can indefinitely proliferate in culture they are endowed with a cell-intrinsic property termed mitochondrial priming that renders them highly sensitive to apoptotic stimuli [4].

Cyclin-dependent kinases (CDKs), a family of serine/ threonine protein kinases originally identified as regulators of the eukaryotic cell cycle, can also regulate transcription and, in certain cell types, differentiation $[5,6]$. Until present, $20 \mathrm{CDKs}$ have been characterized and have been separated into two subfamilies: cell-cycle-related 
subfamilies (CDK1, CDK4 and CDK5) and transcriptionassociated subfamilies (CDK7, CDK8, CDK9, CDK11 and CDK20) [6]. The catalytic activity of CDKs essentially depends on their binding to regulatory subunits $[7,8]$. CDKs activity is also modulated by CDK kinases, that include the CDK activating complex CAK (comprising CDK7, cyclin $\mathrm{H}$ and Mat1), by Wee and Myt1 kinases, by CDK phosphatases (CDC25 phosphatases), and by CDK inhibitors (CKIs), including the INK4 $\left(\mathrm{p} 15^{\mathrm{INK} 4 \mathrm{~b}}, \mathrm{p} 16^{\mathrm{INK} 4 \mathrm{a}}\right.$, $\mathrm{p} 18^{\mathrm{INK} 4 \mathrm{c}}$, and $\mathrm{p} 19^{\mathrm{INK} 4 \mathrm{~d}}$ ) and the Cip/Kip (p21 ${ }^{\mathrm{Cip1}}, \mathrm{p} 27^{\text {Kip1 }}$, and $\mathrm{p} 57^{\text {Kip2 }}$ ) families $[5,7]$. Interestingly, it has been shown that hESCs display high levels of CDK activity in part due to the absence or very weak expression of CKIs $[9,10]$.

CDK inhibitors, representing a well-defined group of biologically active compounds, are structurally related to adenosine-5'-triphosphate (ATP). The 2,6,9-trisubstituted purine chemistry defines a family of drugs, such as Olomoucine, Roscovitine (ROSC) and Purvalanol, that selectively inhibit the activities of CDKs by specific binding to their ATP-binding pocket [11]. ROSC is a broad-range purine inhibitor, which effectively inhibits CDK1, CDK2, CDK5, CDK7 and CDK9, but is a poor inhibitor for CDK4 and CDK6 [12, 13]. In proliferating somatic cells, ROSC arrests the cell cycle in G1, S, or in G2/M phases, depending on the cell type used, the concentration and the time of exposure. Although the primary reason for this arrest is the acute inhibition of CDK1 and CDK2 [14], there are several indirect mechanisms by which ROSC can disturb cell cycle progression. The immense majority of these indirect mechanisms arises from changes in gene expression profiles in ROSC-treated cells. It is now known that ROSC decreases transcription by inhibiting CDK7 and CDK9, which are responsible for the phosphorylation of the carboxy-terminal domain (CTD) of the RNA polymerase II largest subunit, an activity that results relevant for transcription initiation and elongation [15].

Furthermore, in some cellular contexts CDK inhibitors can induce programmed cell death [16-18]. In this regard, ROSC appears to have contradictory effects towards apoptosis depending on the cycling status of the cell. In highly dividing cells ROSC stimulates apoptosis; conversely, in non-dividing or differentiating cells this CDK inhibitor exerts a protective effect $[19,20]$. Importantly, to date it has not been fully addressed whether CDKs activities are universally required in apoptotic processes. Nevertheless, despite the absence of a model of CDKs involvement in programmed cell death, there are convincing data that suggest that its activities are required in a subset of apoptosis programs in certain cell types [21]. To this end, potential mechanisms related to the regulation of apoptosis by CDKs that include interactions between the CDKs and the p53 signaling pathways have been described [22, 23]. It thus appear that CDKs have cell-type specific functions and that compensatory roles exist among different CDK family members, which could play important roles in the control of proliferation and apoptosis.

The strict control of cell proliferation and cell death is crucial for embryonic development. Many of the gene products which appear to control apoptotic tendencies are cell cycle regulators; thus, the control of cell death and the one of cell cycle seem to be closely related processes. In this sense, whether CDKs regulate apoptotic processes in rapidly proliferating and apoptosis-prone hESCs remain to be determined, and if so, the underlying mechanisms involved await elucidation. In the present study we found that in hESCs, inhibition of CDKs by ROSC induces cell cycle arrest and apoptosis. The apoptotic effect of ROSC is manifested by the activation of caspase- 9 and caspase- 3 . This CDK inhibitor also led to stabilization and site-specific phosphorylation of p53 at serine 46 concomitantly with down-regulation of murine double minute $2(m d m 2)$ mRNA and protein levels. Moreover, ROSC treatment induces changes in the expression levels of pro-survival Bcl-2 protein, myeloid cell leukemia-1 (Mcl-1) and its BH3-only binding partners: p53-upregulated modulator of apoptosis (PUMA) and phorbol-12-myristate-13-acetate-induced protein 1 (PMAIP1/NOXA) shifting the balance between anti- and pro-apoptotic factors towards cell death. Notably, impairment of CDK2 activity was not a critical event in ROSC-induced apoptosis. Therefore, using small molecule CDK inhibitors we aimed to shed light on the cellular mechanisms that dictate $\mathrm{hESCs}$ fate decisions.

\section{Results}

\section{Onset of cell cycle arrest in hESCs exposed to ROSC}

As previously mentioned, ROSC has the potential to perturb cell cycle progression in G1, S or G2/M depending on the dose and time of exposure in various cell types, ranging from numerous cancer cell lines to keratinocytes and fibroblasts [24, 25]. Thus, to evaluate whether ROSC has the potential to promote cell cycle arrest in asynchronously growing $\mathrm{hESCs}$, we determined the percentage of cells in each phase of the cell cycle after a $16 \mathrm{~h}$ exposure period by quantification of DNA content using PI staining. Flow cytometric analysis revealed that ROSC-treated cells retained a significantly higher proportion of cells in G2/M (40\%) than those treated with DMSO (21\%) (Fig. 1) a. Alternatively, DNA synthesis was analyzed by a biparametric flow cytometry analysis of BrdU incorporation vs. DNA content. As seen in Fig. 1 a BrdU incorporation assays clearly show a marked increase in G2/M population after ROSC treatment (ROSC-treated 37\% vs. DMSO-treated 17\%). This $\mathrm{CDK}$ inhibitor also caused a decrease in the percentage of cells that were actively replicating DNA (S phase). By 


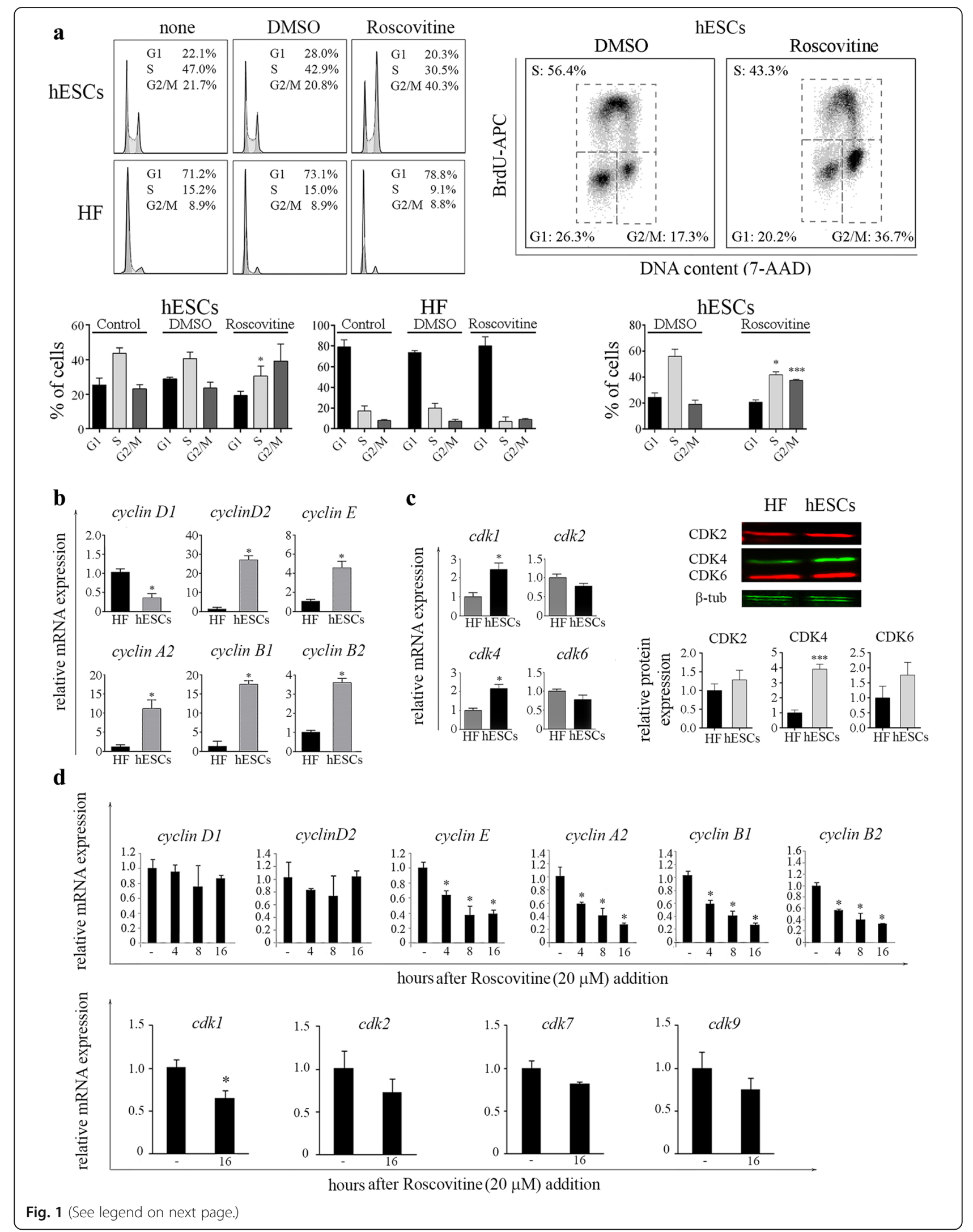


(See figure on previous page.)

Fig. 1 ROSC affects cell cycle distribution and key cell cycle regulators expression. a hESCs were exposed to ROSC or DMSO for $16 \mathrm{~h}$. Cell cycle distribution of asynchronously growing or ROSC-treated H9 and HF was determined by flow cytometry analysis of cellular DNA content following cell staining with PI (left panel). Cells were pulse labeled with BrdU for 30 min prior to harvesting and stained with anti-BrdU-APC conjugate and with7-amino-actinomycin D (7-AAD) for determination of DNA synthesis and DNA content respectively (right panel). Bar graphs summarizing flow cytometry cell cycle profile analysis. Error bars represent means \pm SD from three independent experiments (lower panels). $\mathbf{b}$ Comparison of mRNA expression levels for cyclin D1, D2, E, A2, B1 and B2 in hESCs and HF assessed by Real Time RT-PCR (left panel). Rpl7expression served as normalizer. Graph shows mRNA fold change relative to HF. The mean \pm SEM from three independent experiments are shown. $\mathbf{c}$ Comparison of mRNA expression levels of $c d k 1, c d k 2, c d k 4$ and $c d k 6$ in hESCs and HF analyzed by Real Time RT-PCR (left panel). Representative Western blot images of CDK2, CDK4 and CDK6 (right panel). $\beta$-Tubulin served as loading control. Bar graphs show densitometric quantification. Data are expressed as means \pm SD (left panel). d Time course analysis of mRNA levels of cyclin D1, D2, E, A2, B1, B2 and cdk1, cdk2, cdk7 and cdk9 were assessed by Real Time RT-PCR in ROSC-treated or untreated hESCs. Rpl7 expression served as normalizer. Graph shows mRNA fold change relative to untreated cells. The mean \pm SEM from three independent experiments are shown. In all cases paired Student's $t$ test was used to test for significant differences ${ }^{*} P<0.05,{ }^{* *} P<0.001$

contrast, when HF were exposed to ROSC we observed a slight increase in G1 population with a concomitant decrease in S population (Fig. 1a).

Next, we aimed to compare the mRNA expression levels of key cell cycle regulators in hESCs and HF. To address this issue, we measured different cyclin mRNAs in both cell types by real time RT-PCR. Consistent with previous reports, we determined that cyclin D2 mRNA is the predominant D-type cyclin gene expressed in hESCs (H9) (data not shown) [26]. Additionally, we observed that asynchronously growing hESCs express higher levels of cyclin D2, E, A2, B1 and B2 mRNAs than HF (Fig. $1 \mathrm{~b})$. Then, we analyzed the expression levels of CDK1, CDK2, CDK4 and CDK6 in pluripotent cells and HF. We found that $\mathrm{H} 9$ cells express significantly higher levels of $c d k 1$ and $c d k 4$ mRNAs than HF (Fig. 1c, left panel). We also evaluated the abundance of the major CDKs that are activated during interphase (CDK2, CDK4 and CDK6) by Western blot (Fig. 1c, right panel). We found a good correlation between them mRNA levels and the corresponding protein products in each cell type.

We then tested whether ROSC affects the expression levels of key cell cycle regulators. To do so, we analyzed cyclin D1, D2, E, A2, B1 and B2 mRNAs expression at different time points after ROSC addition $(20 \mu \mathrm{M})$. We determined that almost all cyclins mRNA expression levels were reduced as soon as $4 \mathrm{~h}$ post-treatment respect to those exhibited by DMSO-treated control cells, except for cyclin $D 1$ and $D 2$, whose levels remained fairly constant over the time frame the experiments were conducted. The observation that the transcript levels of essential regulators of $\mathrm{G} 2 / \mathrm{M}$ transition (cyclin $A 2, B 1$ and $B 2$ ) were robustly down-regulated may provide a possible mechanism by which ROSC can cause cell cycle arrest in G2/M phase in pluripotent cells.

Concerning to cell cycle regulation, it has been reported that a pure R-enantiomer of ROSC, CYC202, decreases the expression of several transcripts involved directly or indirectly in cell cycle progression such as
CDK1, CDK7 and CDK9, among others [27]. Thus, to further explore whether ROSC has also the potential to affect the expression levels of these genes in pluripotent cells we performed real time RT-PCR analysis. We found that $c d k 1$ transcript was slightly although significantly down-regulated in hESCs, while $c d k 2, c d k 7$ and $c d k 9$ mRNA levels remained unaffected when challenged with ROSC for $16 \mathrm{~h}$ (Fig. 1d, bottom panel).

\section{ROSC triggers apoptosis of hESCs}

Next, we evaluated the possible effects of ROSC on hESCs and HF viability. To address this issue, we determined the number of viable cells after continuous exposure to ROSC for $16 \mathrm{~h}$ at concentrations ranging from 0 to $20 \mu \mathrm{M}$ using a XTT/PMS vital dye assay. As shown in Fig. 2a no evident effects were observed with ROSC at 1 to $10 \mu \mathrm{M}$, but cell viability was strongly reduced in the presence of ROSC at $20 \mu \mathrm{M}$. The percentage of surviving cells decreased to approximately $40 \%$ after $16 \mathrm{~h}$ of ROSC $(20 \mu \mathrm{M})$ addition. Moreover, cell death induction by ROSC $(20 \mu \mathrm{M})$ treatment was further demonstrated by Trypan blue dye-exclusion (Fig. 2a, right panel) and PI staining assays (Fig. 2b, right panel). Conversely, ROSC treatment did not affect the viability of HF at least at the concentrations and periods assayed.

Furthermore, the loss of cell viability was accompanied by changes in cell morphology that included cell detachment and ballooning, both signature features of apoptosis (Fig. 2b, left panel). Hence, to evaluate whether exposure of $\mathrm{H} 9$ cells to ROSC led to caspase activation we performed Western blot analysis and found that $4 \mathrm{~h}$ after treatment, pro-caspase-9 $(47 \mathrm{kDa})$ was processed generating active fragments $(37 / 35 \mathrm{kDa})$ (Fig. 2c). Once activated caspase- 9 can further cleave and activate downstream effector caspases such as caspase-3. Thus, to further characterize the apoptotic events initiated by ROSC, we used a specific antibody that detects cleaved caspase- 3 and determined that this caspase was activated $4 \mathrm{~h}$ onwards after treatment (Fig. 2c). Active caspase-3 can cleave downstream substrates involved in apoptotic 
$\mathbf{a}$
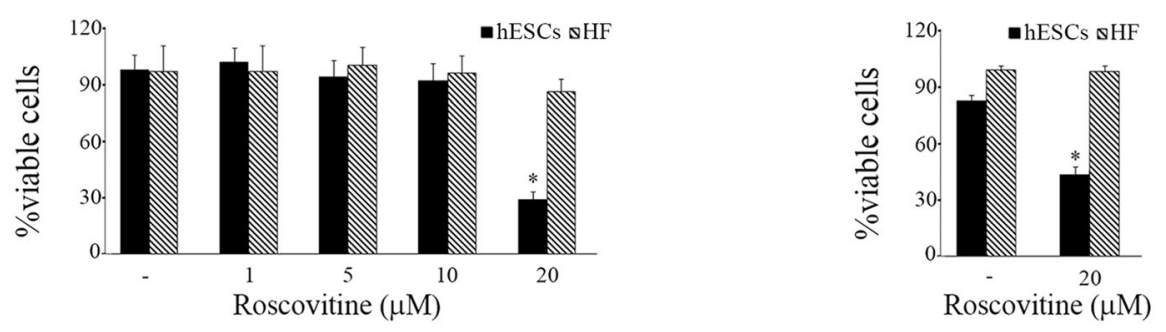

$\mathbf{b}$

Roscovitine $(\mu \mathrm{M})$
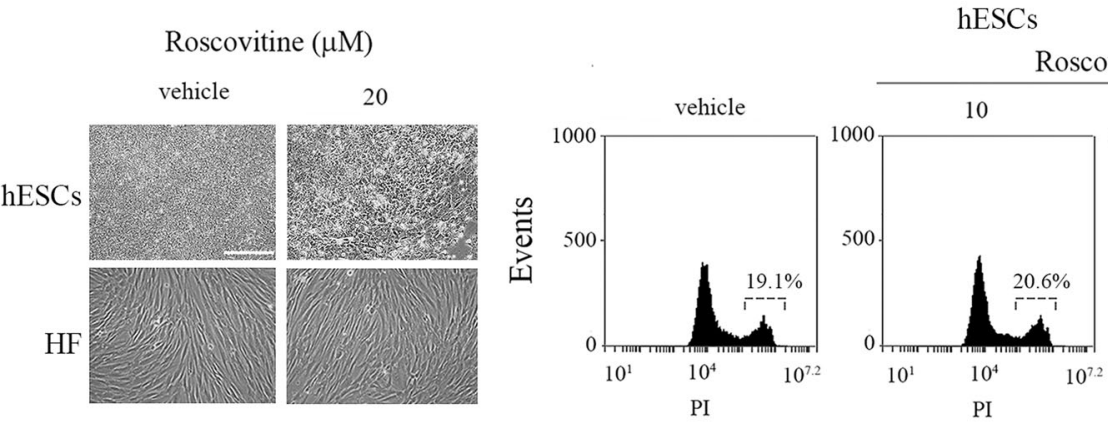

Roscovitine $(\mu \mathrm{M})$

hESCs

c

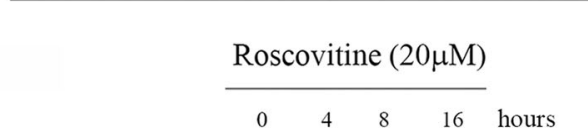

Procaspase-9 cleaved caspase-9

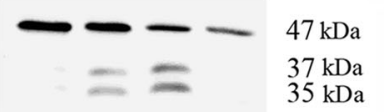

$$
\begin{array}{r}
\text { cleaved } \\
\text { caspase-3 }
\end{array}
$$

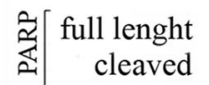

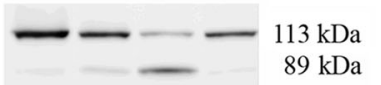

$$
\text { GAPDH }
$$

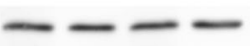

e

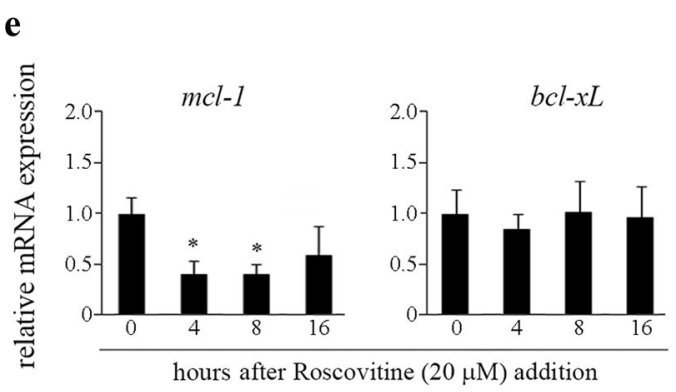

d

\section{Roscovitine $(20 \mu \mathrm{M})$}

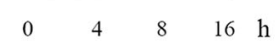

Actin

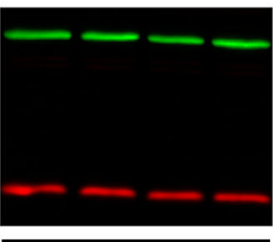

Actin

Bcl-xL

Actin

Mcl-1
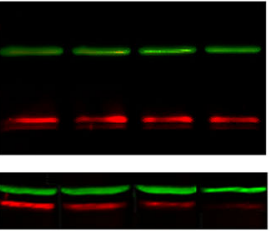

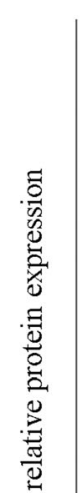

\section{f}

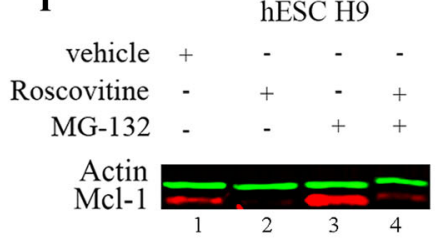

HF

Actin Mcl-1

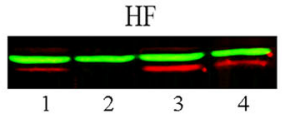

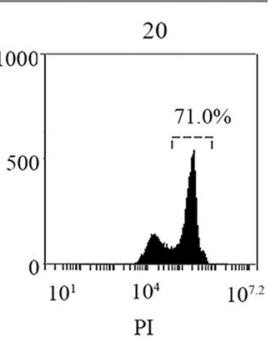

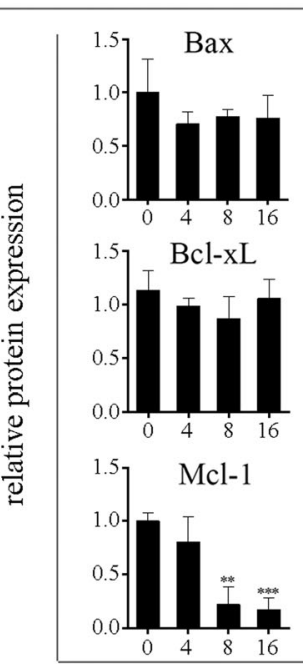

hours after Roscovitine addition

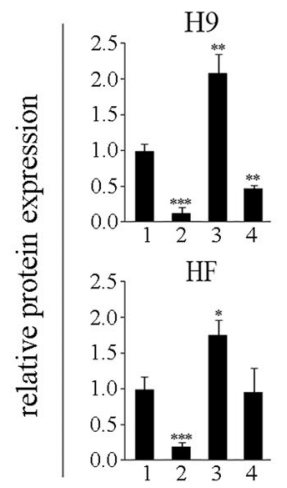

Fig. 2 (See legend on next page.) 


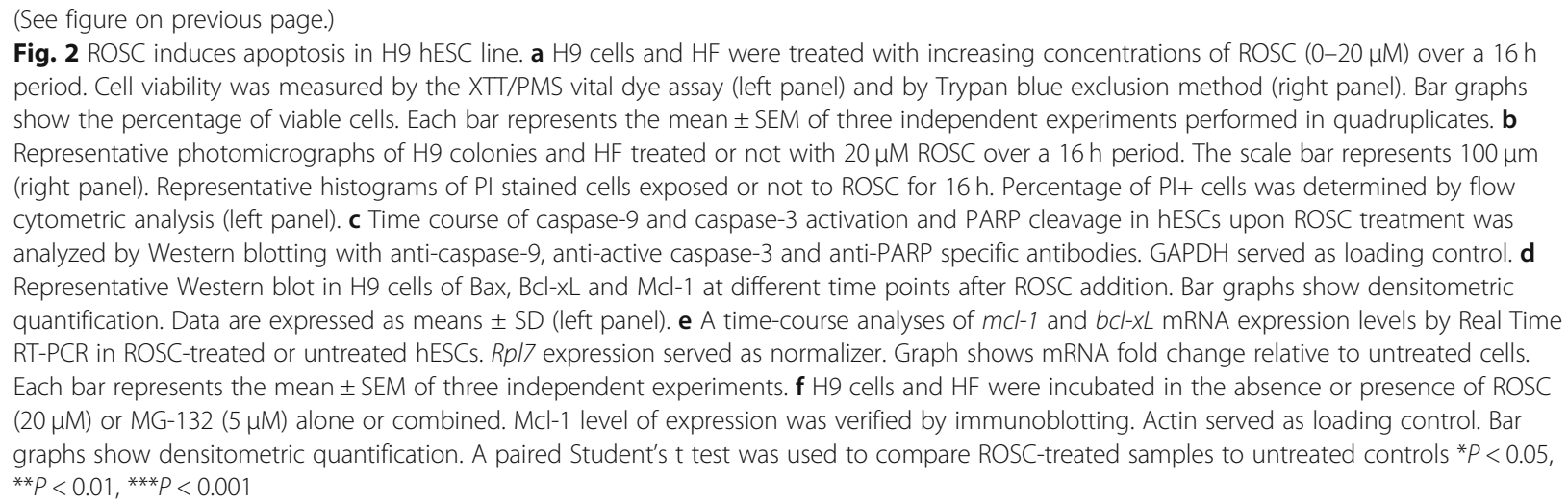

processes such as poly-(ADP-ribose) polymerase (PARP). Time course experiments revealed the presence of the 89 $\mathrm{kDa}$ fragment of PARP $8 \mathrm{~h}$ after ROSC addition (Fig. 2c).

\section{CDK inhibition reduces expression of the anti-apoptotic Bcl-2 family member Mcl-1 in hESCs}

The presence of cleaved caspase- 9 indicates that ROSC induces apoptosis through activation of the mitochondrial pathway in hESCs. Thus, we assessed the consequences of ROSC treatment on the expression of key mitochondrial-mediated apoptotic players such as Bax, $\mathrm{Bcl}-\mathrm{xL}$ and Mcl-1. By Western blot analysis we found that there were no substantial changes in Bax or Bcl-xL protein expression levels (Fig. 2d). Conversely, we determined that Mcl-1 levels were markedly reduced in $\mathrm{H} 9$ cells at $8 \mathrm{~h}$ post treatment and onwards (Fig. 2d). In this regard, we found that in hESCs ROSC also led to a decrease of $m c l-1 \mathrm{mRNA}$ levels without affecting $b c l-x L$ transcripts (Fig. 2e). Previous reports have shown that ROSC treatment led to the down-regulation of $\mathrm{mcl}^{-1}$ mRNA levels and the loss of Mcl-1 protein product by a mechanism that can be impaired by drugs that inhibit the proteasome [28]. In this regard, we determined that exposure to proteasome inhibitor MG-132 $(5 \mu \mathrm{M})$ prevented loss of Mcl-1 protein levels in hESCs and HF, even in the presence of ROSC (Fig. 2f).

\section{ROSC activates p53 pathway in hESCs}

p53 is a key molecule involved in the regulation of cell cycle progression and the induction of apoptosis in numerous cell types. The activity of this protein is controlled at multiple levels, including protein stability and subcellular localization. Interestingly, it has been reported that substituted purines such as ROSC, mimicking the ATP molecule, activate p53 protein [29]. The above consideration prompted us to explore whether ROSC induces changes in p53 protein level in H9 cells. To address this issue, ROSC-treated $(20 \mu \mathrm{M})$ hESCs were harvested at different time points and subjected to Western blot assays. As shown in Fig. 3a, enhanced levels of p53 were seen following a $4 \mathrm{~h}$ treatment with ROSC and onwards. In parallel, we assessed subcellular localization of p53 after ROSC treatment. Immunofluorescent staining revealed a diffuse pattern of p53-immunoreactivity in untreated hESCs and a clear nuclear localization in ROSC-treated counterparts (Fig. 3b).

To address whether the increase in nuclear p53 was accompanied by an increase in p53 transcriptional activity, the levels of four well characterized p53-responsive genes (Mdm2, p21 ${ }^{\mathrm{Cip} 1}$, PUMA and PMAIP1/NOXA) were measured by quantitative RT-PCR in ROSC-treated and untreated hESCs [30]. As shown in Fig. 3c, a robust induction of $p 21^{C i p 1}$ and, to a lesser extent, puma and noxa mRNAs expression levels were determined after $20 \mu \mathrm{M}$ ROSC addition. Unexpectedly, we found that the levels of the well-known negative regulator of p53, $m d m 2$ transcript declined after treatment. The observed decrease in $m d m 2$ mRNA levels was reflected at the protein product as judged by Western blot analysis (Fig. 4a, left panel). In order to gain insight into the involvement of p53 in the regulation of Mdm2 gene in $\mathrm{H} 9$ cells we used siRNA-mediated gene silencing. We assessed the efficacy of the p53-trageting siRNA by real time RT-PCR in cells transfected with either non targeting control siRNA (NT-siRNA) or p53 specific siRNA. As shown in Fig. 4a, a significant decrease in p53 mRNA levels was observed in p53-siRNA transfectants. We found that siRNA-mediated downregulation of p53 led to a reduction of $m d m 2$ mRNA levels in hESCs. Additionally, we determined that the p53 targeting-siRNA cooperated with ROSC to further reduce Mdm2 levels (Fig. 4a). Importantly, these results suggest that in hESCs, ROSC selectively inhibits the expression of $m d m 2$, which may lead to the observed stabilization and accumulation of $\mathrm{p} 53$. These findings are consistent with previous data showing that ROSC exposure decreased the rate of $m d m 2$ transcription [31]. As expected, cell death was reduced from $61.45 \pm 1.85 \%$ in NT-siRNA transfected cells 


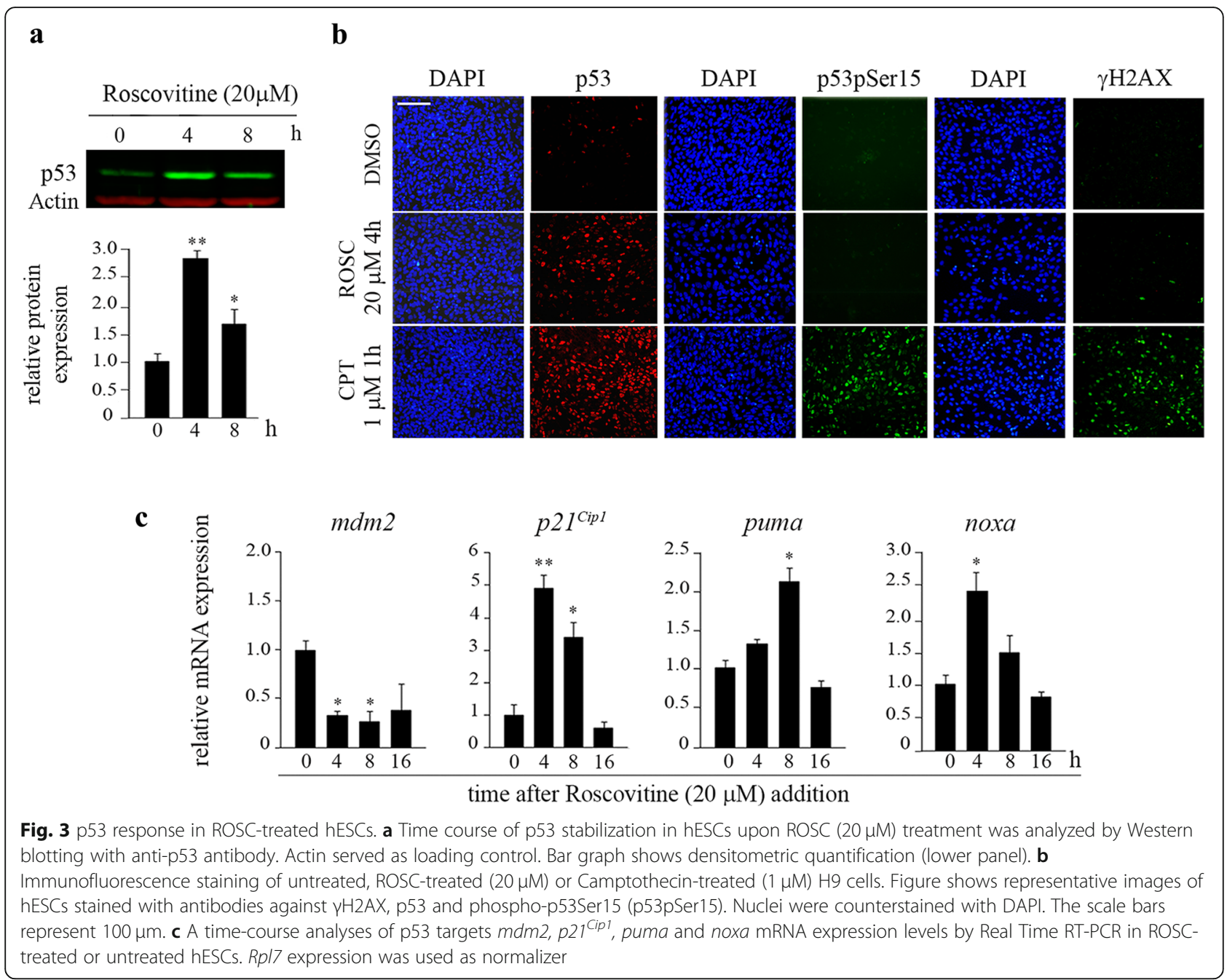

to $40.55 \pm 2.95 \%$ in p53-siRNA transfected cells after ROSC treatment (Fig. 4b). Importantly, the fact that H9 cells with p53 mRNA levels reduced by approximately $50 \%$ exhibit a lower rate of cell death after ROSC exposure, suggests that p53 is a relevant player in the regulation of pluripotent cells apoptosis.

Post-translational modifications of specific residues contribute to p53 stabilization and are thought to determine the choice among the several p53-regulated programs [32]. Phosphorylation is also important for stabilization of p53 under certain stress conditions. Thus, in order to determine whether the nuclear accumulation of p53 in response to ROSC was accompanied by phosphorylation events, we performed immunofluorescence assays using a specific antibody against phospho-p53 serine15 (p53pSer15). In contrast to what we observed in camptothecin treated cells $(1 \mu \mathrm{M}$ for $1 \mathrm{~h}$ ) (used as a positive control), the p53 proteins that accumulated in the nuclei after ROSC treatment $(20 \mu \mathrm{M}$ for $4 \mathrm{~h})$ were not phosphorylated at the serine 15 site (Fig. 3b).
This was previously described in human diploid fibroblasts exposed to ROSC [33]. Consistent with the lack of p53 phosphorylation at serine 15, no appreciable $\gamma \mathrm{H} 2 \mathrm{AX}$ immunoreactivity (a marker of DNA damage) was observed in ROSC treated cells. Conversely, a robust induction of $\gamma \mathrm{H} 2 \mathrm{AX}$ was observed in camptothecin treated H9 cells (Fig. 3b).

Phosphorylation of p53 at serine 46 is an important cell fate determining factor promoting p53-mediated transcriptional activation of pro-apoptotic genes [34]. To further investigate whether ROSC induces any other phosphorylation of p53 we performed Western blot analysis using antibodies against phospho-p53 serine 46 (p53pSer46). As shown in Fig. 4c, phosphorylation at this residue was detectable $4 \mathrm{~h}$ after ROSC addition resulting more evident at $16 \mathrm{~h}$ post treatment. Thus, although p53 accumulated in the nucleus after exposure either to camptothecin or ROSC, modification of p53 at serine 15 appears to be mainly associated with genotoxic stress rather than with CDK inhibition in this 


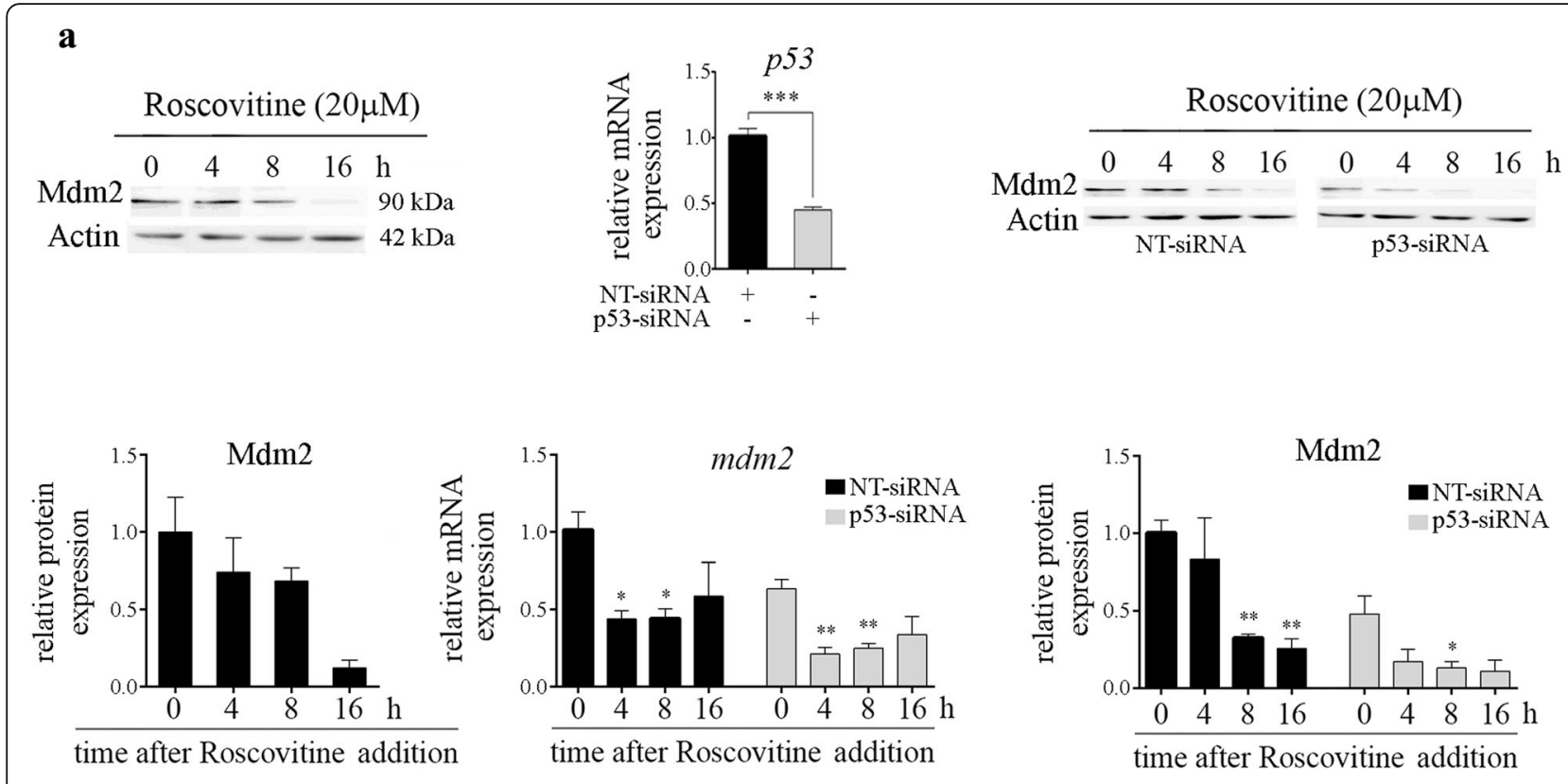

b

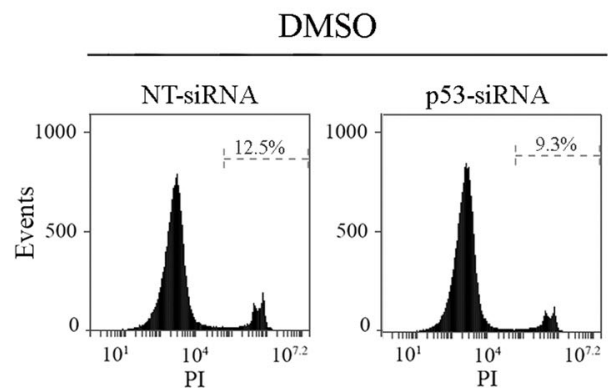

c

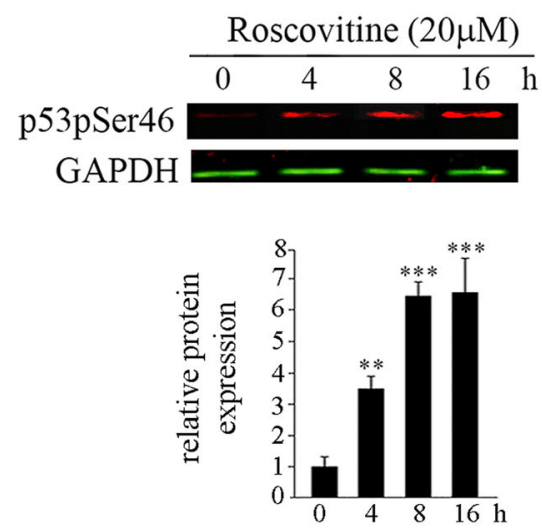

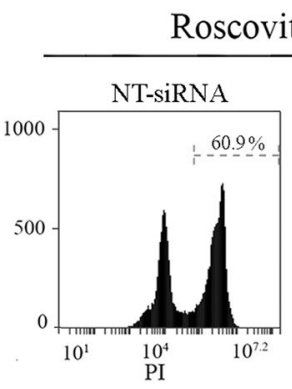
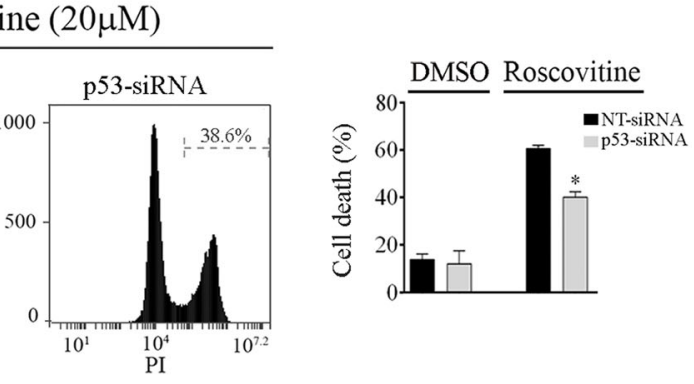

Fig. 4 (See legend on next page.)

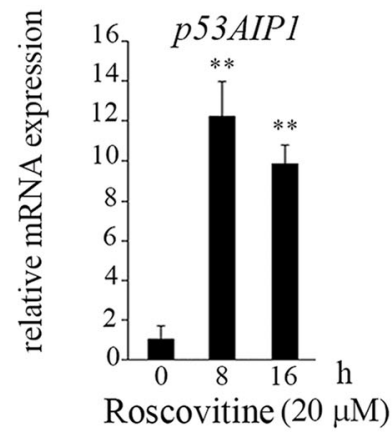

d

Roscovitine $(20 \mu \mathrm{M})$

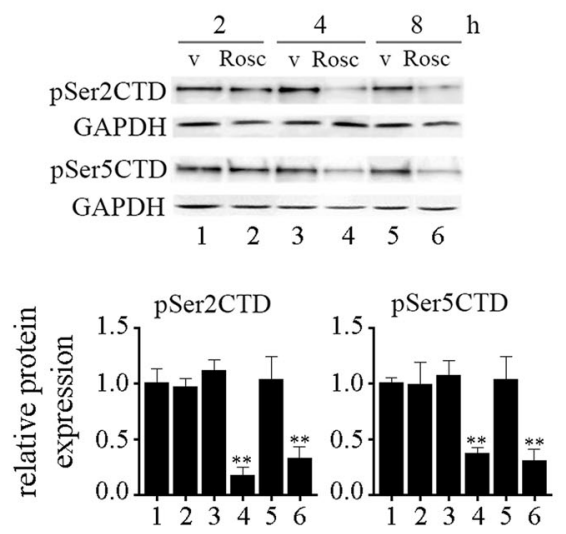

e 


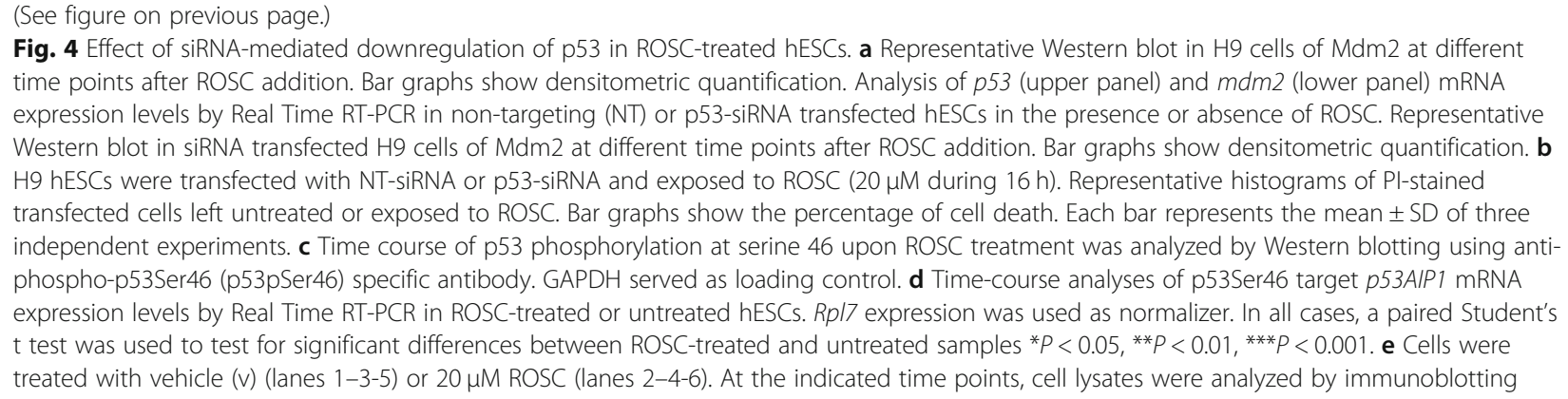

cell type. Besides, serine 46 phosphorylation is found to play a critical role in p53-mediated apoptotic genes induction such as p53-regulated Apoptosis-Inducing Protein 1 (p53AIP1) [34]. To this end, we examined whether p53AIP1 mRNA levels were induced upon ROSC treatment. Real time quantitative RT-PCR analysis revealed a strong induction of p53AIP1 transcripts from about $8 \mathrm{~h}$ onwards after ROSC exposure (Fig. 4d).

\section{ROSC modulates phosphorylation status of the CTD of the RNA polymerase II in hESCs}

Assessment of the phosphorylation status of the CTD of the largest subunit of the RNA polymerase II, which is composed of 52 repeats of the consensus heptapeptide Tyr1- Ser2-Pro3-Thr4-Ser5-Pro6-Ser7, offers a functional assay to test CDK7 and CDK9 activities. CDK7 phosphorylates RNA pol II serine 5, whereas CDK9 phosphorylates predominantly serine 2 (though it can phosphorylate both under certain conditions in different cell types). Phosphorylation on these residues is of known importance to the regulation of transcription by CDK7 and CDK9 [35-37]. To investigate whether ROSC was affecting the activation of RNA pol II in H9 cells we analyzed the levels of RNA polymerase II phosphorylated at serine 2 and serine 5 by Western blotting. As shown in Fig. 4e, a significant time-dependent loss of phosphorylation at serine 2 and 5 residues was observed when hESCs were incubated with ROSC. These results suggest that, as occurs in several cell types [38], ROSC is inhibiting transcriptional CDKs in hESCs. These findings are further supported by the decline of short-lived mRNAs such as $m d m 2$ and $m c l-1$. Worth noting, we observed that even though ROSC exposure markedly reduced the phosphorylation of serine 2 and 5 within the CTD of RNA Pol II, the presence of this CDK inhibitor led to a significant increase in the levels of $p 21^{C i p 1}$, puma, noxa and p53AIP1 mRNAs.

\section{Inhibition of CDK2 did not induce cell death in hESCs}

We then asked whether inhibition of CDK2 would result in similar effects as those seen after ROSC treatment in
hESCs. To address this question, we exposed pluripotent cells to $5 \mu \mathrm{M}$ CDK2 inhibitor II for $24 \mathrm{~h}$. To confirm the effectiveness of this small-molecule inhibitor we performed Western blot analysis to evaluate cyclin E abundance in CDK2 inhibitor II-treated H9 cell, as it has been shown that raised cyclin $\mathrm{E}$ levels are a reflection of inactive CDK2 [39]. Scanning densitometries of immunoblots revealed a significant increase in cyclin $\mathrm{E}$ protein levels in $\mathrm{H} 9$ cells exposed to this CDK2 inhibitor when compared to that determined in untreated counterparts. This result has been previously reported by our group [40]. Importantly, when CDK2 activity was impaired no considerable changes in hESCs viability and morphology were observed (Fig. 5a). Moreover, the protein levels of p53 and Mcl-1 did not vary significantly upon CDK2 inhibition (Fig. 5a) and no alterations on cell cycle distribution were detected (data not shown). These findings are in accordance with previous studies describing that knockdown of CDK2 in mouse ESC had little effect on cell cycle and did not significantly affect their viability [17]. Then, we assessed the ability of this CDK2 inhibitor to influence the expression of pluripotency markers in hESCs. As illustrated in Fig. 5b, no appreciable changes in the expression levels of Oct-4 and Nanog were observed after a $72 \mathrm{~h}$ exposure.

\section{Discussion}

CDKs, are important regulators of the cell cycle, have well-defined roles in transcription regulation and debatable roles in apoptosis. Currently, the role of CDKs in regulating hESCs proliferation and viability has not been fully addressed. For this reason, in the present study we aim to investigate the effects triggered by ROSC, a wellknown CDK inhibitor, in hESCs.

Herein, we demonstrated that hESCs are sensitive to the anti-proliferative effects of ROSC. One of the most prominent effects of ROSC is the inhibition of CDK2 and CDK1, even though, many studies have provided evidence that the anti-proliferative effects of ROSC are produced by its ability to target several CDKs rather than only one of them [15]. 
a

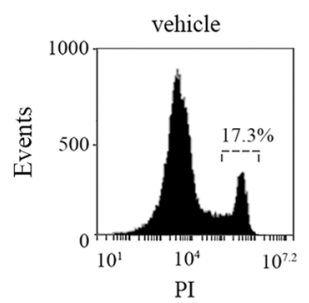

vehicle

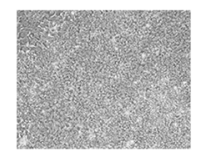

CDK2 inh II

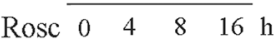

GAPDH
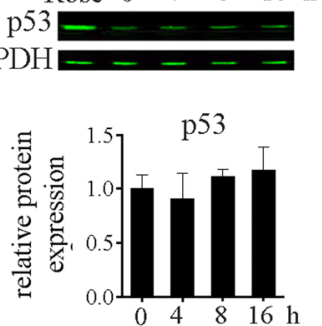

time after CDK2 inhII $(5 \mu \mathrm{M})$ addition

b
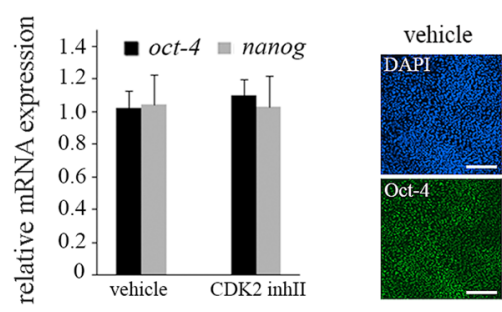

CDK2 inhII

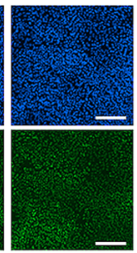

Fig. 5 Small molecule inhibition of CDK2 did not induce cell death in hESCs. a Representative histograms of PI stained cells exposed or not to CDK2 inhibitor II $(5 \mu \mathrm{M})$ for $24 \mathrm{~h}$. Percentage of Pl+ cells was determined by flow cytometric analysis (top panel). Representative photomicrographs of $\mathrm{H} 9$ colonies and $\mathrm{HF}$ treated or not with $5 \mu \mathrm{M}$ CDK2 inhibitor II over a $24 \mathrm{~h}$ period (bottom left panel). p53 and Mcl-1 protein levels were analyzed in the presence or absence of CDK2 inhibitor by Western blot. GAPDH and Actin were used as loading controls. Bar graphs show densitometric quantification (bottom right panel). b Pluripotency markers oct-4 and nanog mRNA expression levels by Real Time RT-PCR in CDK2 inhibitor II-treated or untreated (vehicle) hESCs. Rpl7 expression was used as normalizer (right panel). The mean \pm SEM from three independent experiments are shown. In all cases, a paired Student's t test was used to test for significant differences between ROSC-treated and untreated samples. ${ }^{*} P<0.05$. Immunofluorescence photomicrographs of CDK2 inhibitor II-treated $\mathrm{H} 9$ cells (5 $\mu \mathrm{M}$ during $72 \mathrm{~h}$ ). Representative images of $\mathrm{H} 9$ cells stained with primary antibody against Oct-4. Nuclei were counterstained with DAPI. Scale bars represent $100 \mu \mathrm{m}$

Suppressed transcription and decreased phosphorylation of RNA pol II were documented in cells treated not only with ROSC but also with other CDK inhibitors $[27,41]$. In this regard, we observed a marked reduction in the phosphorylation levels of serine 2 and serine 5 residues (targets of transcriptional CDKs) within the CTD of RNA pol II upon ROSC treatment. Labile transcripts, as those with short half-lives encoding cell cycle and apoptosis regulators, are most sensitive to CDK-mediated transcriptional inhibition as their levels rapidly decrease upon transcription inhibition. In this regard, we determined a marked decrease in cyclin $E, A 2, B 1, B 2$ and $c d k 1$ mRNA expression levels in hESCs exposed to ROSC, presumably due to its ability to affect CDK7/9dependent transcription. In this context, it is conceivably that the observed alterations in the expression levels of key cell cycle regulators may significantly contribute to the cell cycle arrest induced by CDK inhibition.

Importantly, we also demonstrated that ROSC triggers apoptosis in hESCs but not in primary fibroblasts, and found that the apoptotic process encompasses caspase-9 and -3 activation and PARP cleavage. As occurred in several cell types [42] we found that ROSC led to Mcl-1 down-regulation in hESCs and FH. Mcl-1 is an important transcriptional target of RNA pol II and a short-lived transcript, therefore repression of transcription may be the cause of its relatively rapid elimination. The fact that Mcl-1 levels can be both rapidly induced and lost places it as an ideal candidate to detect and respond to survival or death signals. The observation that ROSC induced cell death in $\mathrm{H} 9$ cells but not in $\mathrm{FH}$ suggests that these pluripotent cells rely more heavily on $\mathrm{Mcl}-1$ for their survival than FH. In line with this finding, Huskey et al. reported that siRNA knockdown of $m c l-1$ induces cell death in hESCs but not in human embryonic kidney cells (HEK293) [17]. In comparison to other BH3-only proteins, NOXA shows the most restricted potential to sequester anti-apoptotic factors as it preferentially binds to Mcl-1 [43]. Therefore, susceptibility to NOXA-induced cell death mainly relies on $\mathrm{Mcl}-1$ activity relative to other pro-survival Bcl-2 family members [44]. It stands to reason that in ROSC-treated hESCs the observed downregulation of Mcl-1, which was accompanied by up-regulation of noxa, may allow a transient increase in free NOXA concentration. Thus, we suspect this factor may play an important role in ROSC-induced cell death.

Several drugs activate p53 function by partial inhibition of RNA polymerase II-mediated transcription [45-47]. This may be attributed, at least in part, to $m d m 2$ down-regulation, another short-lived transcript that encodes an E3-ubiquitin ligase negatively regulating p53 protein level. In this sense, we found that in $\mathrm{H} 9$ cells ROSC treatment led to p53 stabilization and nuclear localization, which coincided with decreased levels of Mdm2. This phenomenon has been previously observed in different cell lines [31]. We also found that in ROSC-treated hESCs p53 underwent site specific phosphorylation at serine 46. In line with previous reports, this post-transcriptional modification was 
concomitant with a robust induction of p53AIP1 gene expression, a well-known transcriptional target of p53pSer46 [34, 48].

Earlier reports provide evidence that p53 is able to activate select target genes and trigger an apoptotic program when mRNA synthesis is inhibited; it thus appears that in hESCs this transcription-inhibitory effect also varies among p53-regulated promoters, at least at the concentration of ROSC used in our experiments. In fact, we observed that while some p53 target genes including $p 21^{\text {Cip1 }}$, puma, noxa and $p 53 A I P 1$ were clearly up-regulated in ROSC-treated cells, other p53 transcriptional targets such as $m d m 2$ were downregulated. These results suggest that, as previously described for cancer cells [46, 47], in pluripotent cells a specific subset of p53 target genes may bypass the requirement for CDK9 activity and/or RNAP II complete phosphorylation when mRNA synthesis is broadly comprised. It thus appears that hESCs may be endowed with a p53-mediated safeguard mechanism to confront dysfunctions in transcription.

To further elucidate the consequence of CDK inhibition in $\mathrm{H} 9$ cells, we used a small molecule CDK2 inhibitor and found that impairment of CDK2 activity did not have considerable effects on cell proliferation nor in cell death. Our results are consistent with previous findings describing that the loss of CDK2 can be compensated by CDK1, which has been proved to be capable of substituting the missing activity of any other CDK $[10,49]$. Further supporting these findings, Huskey et al. recently described that depletion of cyclin D1, E1, E2, or CDK2 did not have considerable effects on mouse ESC proliferation and did not induce cell death. Nevertheless, in the same study researchers found that CDK1 inhibition significantly increased cell death in mouse ESCs and in two independently derived hESC lines. Concerning to CDK1 inhibition, Canduri et al found, after analyzing the number of hydrogen bonds between ROSC-CDK1 and ROSC-CDK2, that the ROSC-CDK1 complex presents a higher number of intermolecular hydrogen bonds, indicating that this purine analogue has higher affinity for CDK1 than for CDK2 [50]. According to the aforementioned property of ROSC, it is conceivable to hypothesize that the vast majority of the effects triggered by this CDK inhibitor in hESCs may be due to the impairment of CDK1 and transcriptional CDKs activities rather than a cause of CDK2 inhibition. It is also worth mentioning that our results are in stark contrast to those reported by Neganova et al., describing that siRNA-mediated silencing of CDK2 led to changes in $\mathrm{H} 9$ cells morphology, cell cycle profile, expression of pluripotency markers and CKIs [10]. In their study, they showed that down-regulation of key pluripotency markers such as Nanog and Oct- 4 resumed upon restoration of CDK2 expression levels (4 days after transfection and onwards) suggesting a "reversible" onset of differentiation. Thus, it seems that the absence of CDK2 was not compensated by others CDKs in $\mathrm{H} 9$ cells, as the majority of the cells (96.9\%) were arrested at G1 phase after CDK2-siRNA transfection [10].

\section{Conclusion}

hESCs, a promising cell source for research and clinical applications, are very prone to undergo apoptosis; however, the mechanisms underlying this proneness are not fully understood. Herein, we demonstrate that combined inhibition of cell cycle-associated and transcriptional CDKs by ROSC triggers programmed cell death in hESCs but not in somatic cells (FH). The apoptotic process involves caspase- 9 and caspase- 3 activation, PARP cleavage, p53 stabilization and site specific phosphorylation at serine 46, transcriptional induction of p53AIP1 and repression of Mcl-1 concomitant with noxa and puma up-regulation. Furthermore, we determined that the role of CDK2 inhibition seems to be at best accessory, as an active CDK2 was not required to ensure hESCs survival. Our findings broaden the insights into hESCs apoptosis and may be helpful for establishing pro-survival strategies for its use in therapeutic purposes.

\section{Methods \\ Cell culture}

The hESC line, WA09 (H9), was obtained from WiCell Research Institute at low passages. H9 cells line were expanded on an inactivated mouse embryonic fibroblast feeder layer in medium comprised of Dulbecco's Modified Eagle's Medium/Ham's F12 (DMEM/F12) supplemented with $20 \%$ knockout serum replacement (KSR), $2 \mathrm{mM}$ L-glutamine, $2 \mathrm{mM}$ non-essential amino acids, $50 \mu \mathrm{g} / \mathrm{ml}$ streptomycin, $100 \mathrm{U} / \mathrm{ml}$ penicillin, $0.1 \mathrm{mM} \beta$ mercaptoethanol and $4 \mathrm{ng} / \mathrm{ml}$ of basic fibroblast growth factor. All these reagents were obtained from Thermo (Carlsbad, CA, USA). H9 cells were incubated with $1 \mathrm{mg} / \mathrm{ml}$ collagenase IV (Thermo, CA, USA) and seeded into diluted $(1 / 40)$ Matrigel (Corning) -coated dishes containing inactivated mouse embryonic fibroblast conditioned medium. hESCs were routinely screened for Mycoplasma sp. contamination as previously described [51].

Human fibroblasts (HF) were prepared as primary cultures from freshly obtained foreskins after surgery. Surgically discarded tissue was cropped into strips using a sterile scalpel. Strips were subjected to an overnight digestion with dispase (Invitrogen, CA, USA) and then followed by careful removal of the epidermis. The remaining dermis was placed in high glucose DMEM, $10 \%$ FBS (vol/vol). Within 8-10 days outgrowths of fibroblasts appeared. 


\section{Drug treatments}

Cells were seeded $24 \mathrm{~h}$ before incubation with ROSC (Sigma St. Louis, MO, USA). Proteosome inhibitor MG-132 (474, 790, CAS 133407-82-6, Calbiochem, CA, USA) and CDK2 inhibitor II (sc-221,409, Santa Cruz Biotechnology, CA, USA) were also used. Inhibitors were added to cell cultures such that the final DMSO concentrations were kept constant at $0.25 \%(\mathrm{v} / \mathrm{v})$. Cells treated with $0.25 \%$ DMSO were always included as controls.

\section{Cell viability assay}

Cells were seeded in 48 -well plates at a density of $3 \times$ $10^{4}$ cells per well. After $16 \mathrm{~h}$ of treatment, $50 \mu \mathrm{g} /$ well of activated 2,3-bis (2-methoxy-4-nitro-5-sulfophenyl)-5 [(phenylamino) carbonyl]-2 H-tetrazolium hydroxide (XTT) in PBS containing $0.3 \mu \mathrm{g} /$ well of $\mathrm{N}$-methyl dibenzopyrazine methyl sulfate (PMS) were added (final volume $100 \mu \mathrm{l}$ ) and incubated in a humidified atmosphere for $4 \mathrm{~h}$ at $37^{\circ} \mathrm{C}$. Metabolic activity was measured using a spectrophotometer at $450 \mathrm{~nm}$ and subtracting the background absorbance at $690 \mathrm{~nm}$.

\section{Trypan blue staining}

Cells were plated in 6-well plates at a density of $1 \times 10^{5}$ cells $/ \mathrm{ml}$. After treatment, $10 \mu \mathrm{l}$ of the cell suspension (adherent and detached cells) were transferred to a 1.5 $\mathrm{ml}$ tube, stained for $5 \mathrm{~min}$ at room temperature with $0.4 \%$ Trypan blue (Sigma, St. Louis, MO, USA) in $0.85 \%$ saline solution and the mixture incubated for $2 \mathrm{~min}$. Cells stained blue and unstained were counted in a Neubauer hemocytometer.

\section{Immunostaining and fluorescence microscopy}

Cells were rinsed with ice-cold PBS and fixed in PBSA (PBS with $0.1 \%$ bovine serum albumin) with $4 \%$ formaldehyde for $45 \mathrm{~min}$. Cells were washed two times with PBS and permeabilized with $0.1 \%$ Triton X-100 in PBSA with $10 \%$ normal calf serum for $30 \mathrm{~min}$, washed twice and stained with the corresponding primary antibodies. Then, fluorescent dye-labeled secondary antibody along with DAPI were added and cells were incubated for $45 \mathrm{~min}$ at room temperature protected from light. $\mathrm{H} 9$ cells were examined under a Nikon Eclipse TE2000-S and images were acquired with a Nikon DXN1200F digital camera. The following primary antibodies were use: $\alpha-\gamma \mathrm{H} 2 \mathrm{AX}$ (ab2893), $\alpha-\mathrm{p} 53$ (DO-1) (ab1101) (Abcam Inc., Cambridge, MA, USA) and $\alpha$-phospho-p53serine15 (cat.9284) (Cell Signaling Technology, Beverly, MA, USA).

\section{Flow cytometric analysis of cell cycle distribution}

For DNA content analysis, cells were fixed in $70 \%$ ethanol, rehydrated in PBS, and treated for $30 \mathrm{~min}$ with RNase A $(100 \mu \mathrm{g} / \mathrm{ml})$ and for $5 \mathrm{~min}$ with Propidium
Iodide (PI) $(1 \mathrm{mg} / \mathrm{ml})$. Fluorescence intensity was determined by flow cytometry on a BD Accuri C6 flow cytometer (BD Biosciences, San Jose, CA). The percentage of cells in each stage of the cell cycle was assessed by the Flowjo v10.0.7's univariate platform (https://www.flowjo. com/solutions/flowjo/download).

\section{Flow cytometric analysis of bromodeoxyuridine (BrdU) incorporation and cell cycle distribution}

The distribution of cell populations throughout the cell cycle and the fraction of cells capable of incorporating BrdU was determined using the BrdU Flow Kit (BD Biosciences, San Jose, CA, USA). After the corresponding treatment, cells were incubated with $\operatorname{BrdU}(10 \mu \mathrm{M})$ for $30 \mathrm{~min}$. Cultures were processed as per manufacturer's instructions. Fluorescence intensity was quantified on a BD Accuri C6 flow cytometer. Data were analyzed using BD AccuriC6 software.

\section{Flow cytometric analysis of cell viability using PI}

After $16 \mathrm{~h}$ of ROSC treatment single-cell suspensions were obtained by treatment with accutase $\left(37^{\circ} \mathrm{C}\right.$ for 5 $10 \mathrm{~min}$ ). Cells were then centrifuged at $200 \mathrm{x} \mathrm{g}$ for $5 \mathrm{~min}$ and resuspended up to $10^{6}$ cells $/ \mathrm{ml}$ in FACS Buffer $(2.5$ $\mathrm{mMCaCl}_{2}, 140 \mathrm{mM} \mathrm{NaCl}$ and $10 \mathrm{mM}$ HEPES, $\mathrm{pH}$ 7.4). Next, $100 \mu \mathrm{l}$ of cellular suspension were incubated with $5 \mu \mathrm{l}$ of PI $(50 \mu \mathrm{g} / \mathrm{ml})$ in PBS for $5 \mathrm{~min}$ protected from light. Finally, $400 \mu \mathrm{l}$ of FACS Buffer were added to each tube and cells were analyzed by flow cytometry. Results were expressed as the percentage of cells that displayed PI fluorescence (non-viable) to the total number of cells processed. Fluorescence intensity was determined on a BD Accuri C6 flow cytometer. Data were analyzed using BD AccuriC6 software.

Reverse transcription polymerase chain reaction and real time PCR

Total RNA was extracted using TRIzol reagent (Thermo, Carlsbad, CA, USA) as per manufacturer's instructions. cDNA was synthesized using MMLV reverse transcriptase (Promega, Madison, WI, USA) from $500 \mathrm{ng}$ of total RNA. Quantitative PCR studies were conducted using SYBR $^{\circ}$ Green-ER ${ }^{\mathrm{Tw}}$ qPCRSuperMix UDG (Thermo, Carlsbad, CA, USA).

Primers used were the following: Cyclin A2 forward 5' CCTGCAAACTGCAAAGTTGA-3', reverse 5'-AAAGGC AGCTCCAGCAATAA-3'; Cyclin B1 forward 5'-CAAGCC CAATGGAAACATCT-3', reverse 5'-GGATCAGCTC CATCTTCTGC-3', Cyclin B2 forward 5'-ACTGCTCTGC TCTTGGCTTC-3', reverse 5'- TTTCTCGGATTTGG GAACTG-3'; Cyclin D1 forward 5'-GATCAAGTGTGACC CGGACT-3', reverse 5'-TCCTCCTCCTCTTCCTCCTC3'; Cyclin D2 forward 5'-TTGTTCCCGAGCGATAGATG3', reverse 5' - ACCAGAAGCGAAGAGTAACC-3'; Cyclin E forward 5'-AGGGGACTTAAACGCCACTT-3', reverse 
5'-AGGGGACTTAAACGCCATT-3'; CDK1 forward 5'GCTGGCTCTTGGAAATTG-3', reverse 5'-GTTAGT CAATGGGTATGGTAG-3'; CDK2 forward 5'-CCCTTT CTTCCAGGATGTGA-3', reverse 5' ${ }^{\prime}$-TGAGTCCAAA TAGCCCAAGG-3'; CDK4 forward 5'-TGCAACACCT GTGGACATGTG-3', reverse 5-' ATTTGCCCAACTGG TCGG-3'; CDK6 forward 5'-TCCCTCCTTTGAAGTGGA TG-3', reverse $5^{\prime}$-GTCACCTGGGGCTAAATGAA-3'; CDK7 forward 5'-GTCTCGGGCAAAGCGTTATG-3', reverse 5 '-TTGGTTGGTGTTCTTATCTCTGG-3'; CDK9 forward 5'-CACCAACTCGCCCTCATC-3', reverse 5'GCCTGTCCTTCACCTTCC-3'; Mcl-1 forward 5'-GGGC AGGATTGTGACTCTCATT-3', reverse 5'-GATGCA GCTTTCTTGGTTTATGG-3'; Bcl-xL, forward 5'-TGC GTGGAAAGCGTAGACAAG-3', reverse 5'-GTGGGA GGGTAGAGTGGATGG-3'; p21 ${ }^{\text {Cip1 }}$ forward 5'-CCGAAG TCAGTTCCTTGTGG-3', reverse $5^{\prime}$-GGA TTAGGG CTTCCTCTTGG-3'; Mdm2 forward 5'-GAATCATCGA CTCAGGTACATC-3', reverse 5'-TCTGTCTCACTAAT TGCTCTCCT-3; RPL7 forward 5' -.AATGGCGAGGATGG CAAG-3'; reverse 5'-TGACGAAGGCGAAGAAGC-3'; Puma, forward 5'-GACCTCAACGCACAGTACGAG-3', reverse 5'-AGGAGTCCCATGATGAGATTGT-3'; NOXA, forward 5' -ACCAAGCCGGATTTGCGATT-3', reverse 5'ACTTGCACTTGTTCCTCGTGG-3'; p53AIP1, forward 5'-CACCCACCCGTTGCCTTC-3', reverse 5'-GCTGAG TTCCTGCCTGTCC-3'. All samples were analyzed using an StepOnePlus Real Time PCR System (Applied Biosystems, Foster City, CA, USA) and were normalized to RPL7 gene expression.

\section{Western blotting}

Cells were lysed in ice-cold radio-immunoprecipitation assay buffer supplemented with a protease and phosphatase inhibitor mixture, and protein concentration was determined using Bicinchoninic Acid Protein Assay (Pierce $^{\mathrm{Tw}}$, Rockford, IL, USA). Equal quantities of protein were subjected to $12 \%$ SDS-PAGE, and transferred to PVDF-FL membrane (Millipore, Billerica, MA, USA). The blot was blocked for $1 \mathrm{~h}$ in Odyssey blocking buffer (LI-COR Biosciences, Lincoln, NE, USA) containing $0.1 \%$ Tween 20 and incubated overnight at $4{ }^{\circ} \mathrm{C}$ in Odyssey blocking buffer, $0.05 \%$ Tween 20 and the corresponding primary antibodies. The blot was washed $4 \times 5$ min with Tris-buffered saline (TBS), $20 \mathrm{mM}$ Tris$\mathrm{HCl}, \mathrm{pH} 7.5,500 \mathrm{mM} \mathrm{NaCl}$ ) containing $0.1 \%$ Tween 20 (TTBS), incubated for $1 \mathrm{~h}$ in Odyssey blocking buffer, $0.2 \%$ Tween 20 and IR-Dye labeled secondary antibodies (1:20.000, LI-COR Biosciences, Lincoln, NE, USA) and washed $4 \times 5 \mathrm{~min}$ in TTBS, $1 \times 5 \mathrm{~min}$ in TBS. The blot was scanned using the $680 \mathrm{~nm}$ and $780 \mathrm{~nm}$ channels at a scanning intensity of 4 . Antigen-antibody complexes were visualized using the Odyssey Infrared Imaging System (LI-COR). The following primary antibodies were used: $\alpha$-Actin (sc-1616), $\alpha$-Bax $(\mathrm{N}-20)$ (sc-493), $\alpha-\mathrm{BclX}_{\mathrm{S}} /_{\mathrm{L}}(\mathrm{S}-18)$ (sc-634), $\alpha-\mathrm{Mcl}-1$ (S-19) (sc-819), $\alpha$-CDK2 (M-2) (sc-163), $\alpha$-CDK4 (H22) (sc-601), $\alpha$-CDK6 (C-21) (sc-177) (Santa Cruz Biotechnology), $\alpha$-phosphop53serine46 (cat.2521) (Cell Signaling Technology, Beverly, MA, USA), $\alpha$-p53 (DO-1) (ab1101) (Abcam Inc., Cambridge, MA, USA). Antigen/primary antibody complexes were detected with near infrared-fluorescence-labeled, IR-Dye $800 \mathrm{CW}$ or IR-Dye $680 \mathrm{RD}$, secondary antibodies (LI-COR Biosciences, Lincoln, NE, USA). In some cases, after electrophoresis proteins were transferred to a PVDF membrane (Bio-Rad, Hercules, CA, USA). Blots were blocked $1 \mathrm{~h}$ at room temperature in TTBS containing low-fat dry milk (5\%). Membranes were incubated with the corresponding primary antibodies at $4{ }^{\circ} \mathrm{C}$ for $12 \mathrm{~h}$ in blocking buffer (3\% low-fat dry milk in TTBS). Immunocomplexes were detected using the corresponding horseradish peroxidase-conjugated secondary antibodies and enhanced chemiluminescence reagents (SuperSignal West FemtoSystem, Thermo Scientific, Rockford, IL, USA). The following primary antibodies were used: $\alpha$ PARP (sc-8007), $\alpha$-Mdm2 (sc-965) and $\alpha$-Actin (sc-1616) (Santa Cruz Biotechnology, Santa Cruz, CA, USA), $\alpha-$ active Caspase-3 (ab13847) (Abcam Inc., Cambridge, MA, USA), $\alpha$-caspase-9 (cat. 9502) and $\alpha-M c l-1$ (cat.94296) (Cell Signaling Technology, Beverly, MA, USA) and $\alpha$ phospho-RNA Polymerase II CTD Ser2 and Ser5 were a generous gift from Dr. A Kornblihtt, School of Sciences, University of Buenos Aires, Argentina. The following secondary antibodies were used: a horseradish peroxidaseconjugated $\alpha$-rabbit IgG; $\alpha$-mouse IgG or $\alpha$-goat IgG. Densitometric quantification of immunoreactive bands was done by normalizing protein levels to that of the respective loading control, and the signal recorded for control cells was arbitrarily set to 1 . Data shown are representative of three separate studies and expressed as means $\pm \mathrm{SD}$.

\section{Cell transfection and RNA interference}

H9 cells were transfected with the corresponding siRNA using Lipofectamine RNAiMAX Transfection Reagent (Invitrogen, Carlsbad, CA) as per the manufacturer's specifications. Briefly, $2 \times 10^{5}$ cells/well (six-well plate) were transfected with Silencer Select Negative Control \#2 (Ambion, cat. 4,390,846) or TP53 Silencer $^{\circ}$ siRNA (Ambion, siRNA ID: 106141). Twenty-four hours after transfection cells were treated according to requirements. Knockdown efficacy was analyzed by real time RT-PCR.

\section{Statistical evaluation}

All of the results are expressed as the mean \pm SEM. The student's paired $t$ test was used to determine significant differences between means, and $P$ values below 0.05 were considered to be statistically significant. 


\section{Abbreviations}

CDK: Cyclin dependent kinase; CTD: Carboxy-terminal domain; hESCs: human embryonic stem cells.

\section{Acknowledgements}

The authors would like to thank Damian D. Fernandez Espinosa for his skillful technical assistance.

\section{Authors' contributions}

GAVR: involved in the conception of the research idea, laboratory work, interpretation of the results, preparation and editing of manuscript, VAF: laboratory work, interpretation of the results, CPG: laboratory work, OMH laboratory work and data analysis GES, LR and MES: involved in the conception of the research idea, data analysis, result interpretation, manuscript preparation and editing. All authors read and approved the final manuscript.

\section{Funding}

This work was supported by research grants from Fundación para la Lucha contra las Enfermedades Neurológicas de la Infancia (FLENI) and did not receive any specific grant from other funding agencies.

\section{Availability of data and materials}

Data sharing is not applicable to this article as no datasets were generated or analysed during the current study.

\section{Ethics approval and consent to participate}

Foreskin human fibroblasts were obtained from surgically discarded tissue. Written informed consent was obtained from patient according to guidelines established by the Ethics Committee of our institution (Comite de Ética en Investigaciones Biomédicas del Instituto FLENI).

\section{Consent for publication}

Not applicable.

\section{Competing interests}

The authors declare that they have no competing interests.

Received: 12 October 2018 Accepted: 19 August 2019

\section{Published online: 28 August 2019}

\section{References}

1. Zwaka TP, Thomson JA. Differentiation of human embryonic stem cells occurs through symmetric cell division. Stem Cells. 2005;23(2):146-9.

2. Filipczyk AA, Laslett AL, Mummery C, Pera MF. Differentiation is coupled to changes in the cell cycle regulatory apparatus of human embryonic stem cells. Stem Cell Res. 2007;1 (1):45-60.

3. Becker KA, Ghule PN, Therrien JA, Lian JB, Stein JL, van Wijnen AJ, et al. Selfrenewal of human embryonic stem cells is supported by a shortened G1 cell cycle phase. J Cell Physiol. 2006;209(3):883-93.

4. Geijsen N. Primed to perish: heightened mitochondrial priming explains hESC apoptosis sensitivity. Cell Stem Cell. 2013;13(4):371-2.

5. Lim S, Kaldis P. Cdks, cyclins and CKIs: roles beyond cell cycle regulation Development. 2013;140(15):3079-93.

6. Malumbres M. Cyclin-dependent kinases. Genome Biol. 2014;15(6):122.

7. Pavletich NP. Mechanisms of cyclin-dependent kinase regulation: structures of Cdks, their cyclin activators, and Cip and INK4 inhibitors. J Mol Biol. 1999; 287(5):821-8.

8. Malumbres M, Harlow E, Hunt T, Hunter T, Lahti JM, Manning G, et al. Cyclin-dependent kinases: a family portrait. Nat Cell Biol. 2009;11(11):1275-6.

9. Kapinas K, Grandy R, Ghule P, Medina R, Becker K, Pardee A, et al. The abbreviated pluripotent cell cycle. J Cell Physiol. 2013;228(1):9-20.

10. Neganova I, Zhang X, Atkinson S, Lako M. Expression and functional analysis of $\mathrm{G} 1$ to $S$ regulatory components reveals an important role for CDK2 in cell cycle regulation in human embryonic stem cells. Oncogene. 2009;28(1):20-30

11. De Azevedo WF, Leclerc S, Meijer L, Havlicek L, Strnad M, Kim SH. Inhibition of cyclin-dependent kinases by purine analogues: crystal structure of human cdk2 complexed with roscovitine. Eur J Biochem. 1997;243(1-2):518-26.

12. Knockaert M, Greengard P, Meijer L. Pharmacological inhibitors of cyclindependent kinases. Trends Pharmacol Sci. 2002;23(9):417-25.
13. Fischer PM, Gianella-Borradori A. Recent progress in the discovery and development of cyclin-dependent kinase inhibitors. Expert Opin Investig Drugs. 2005;14(4):457-77.

14. Horiuchi D, Huskey NE, Kusdra L, Wohlbold L, Merrick KA, Zhang C, et al. Chemical-genetic analysis of cyclin dependent kinase 2 function reveals an important role in cellular transformation by multiple oncogenic pathways. Proc Natl Acad Sci U S A. 2012;109(17):E1019-27.

15. Wesierska-Gadek J, Krystof V. Selective cyclin-dependent kinase inhibitors discriminating between cell cycle and transcriptional kinases: future reality or utopia? Ann N Y Acad Sci. 2009;1171:228-41.

16. Horiuchi D, Kusdra L, Huskey NE, Chandriani S, Lenburg ME, GonzalezAngulo AM, et al. MYC pathway activation in triple-negative breast cancer is synthetic lethal with CDK inhibition. J Exp Med. 2012;209(4):679-96.

17. Huskey NE, Guo T, Evason KJ, Momcilovic O, Pardo D, Creasman KJ, et al. CDK1 inhibition targets the p53-NOXA-MCL1 axis, selectively kills embryonic stem cells, and prevents teratoma formation. Stem Cell Reports. 2015;4(3):374-89.

18. Goga A, Yang D, Tward AD, Morgan DO, Bishop JM. Inhibition of CDK1 as a potential therapy for tumors over-expressing MYC. Nat Med. 2007; 13(7):820-7.

19. Edamatsu H, Gau CL, Nemoto T, Guo L, Tamanoi F. Cdk inhibitors, roscovitine and olomoucine, synergize with farnesyltransferase inhibitor (FTI) to induce efficient apoptosis of human cancer cell lines. Oncogene. 2000; 19(27):3059-68.

20. Borgne A, Versteege I, Mahe M, Studeny A, Leonce S, Naime I, et al. Analysis of cyclin B1 and CDK activity during apoptosis induced by camptothecin treatment. Oncogene. 2006;25(56):7361-72.

21. Golsteyn RM. Cdk1 and Cdk2 complexes (cyclin dependent kinases) in apoptosis: a role beyond the cell cycle. Cancer Lett. 2005;217(2):129-38.

22. Morris EJ, Keramaris E, Rideout HJ, Slack RS, Dyson NJ, Stefanis L, et al. Cyclin-dependent kinases and P53 pathways are activated independently and mediate Bax activation in neurons after DNA damage. J Neurosci. 2001; 21(14):5017-26.

23. Ferguson M, Luciani MG, Finlan L, Rankin EM, Ibbotson S, Fersht $A$, et al. The development of a CDK2-docking site peptide that inhibits p53 and sensitizes cells to death. Cell Cycle. 2004;3(1):80-9.

24. Sroka IM, Heiss EH, Havlicek L, Totzke F, Aristei Y, Pechan P, et al. A novel roscovitine derivative potently induces $\mathrm{G} 1$-phase arrest in platelet-derived growth factor-BB-activated vascular smooth muscle cells. Mol Pharmacol. 2010;77(2):255-61.

25. Cicenas J, Kalyan K, Sorokinas A, Jatulyte A, Valiunas D, Kaupinis A, et al. Highlights of the latest advances in research on CDK inhibitors. Cancers (Basel). 2014;6(4):2224-42.

26. Becker KA, Ghule PN, Lian JB, Stein JL, van Wijnen AJ, Stein GS. Cyclin D2 and the CDK substrate p220(NPAT) are required for self-renewal of human embryonic stem cells. J Cell Physiol. 2010;222(2):456-64.

27. Whittaker SR, Te Poele RH, Chan F, Linardopoulos S, Walton MI, Garrett MD, et al. The cyclin-dependent kinase inhibitor seliciclib (R-roscovitine; CYC202) decreases the expression of mitotic control genes and prevents entry into mitosis. Cell Cycle. 2007;6(24):3114-31.

28. Leitch AE, Lucas CD, Marwick JA, Duffin R, Haslett C, Rossi AG. Cyclindependent kinases 7 and 9 specifically regulate neutrophil transcription and their inhibition drives apoptosis to promote resolution of inflammation. Cell Death Differ. 2012;19(12):1950-61.

29. Wesierska-Gadek J, Schmitz ML, Ranftler C. Roscovitine-activated HIP2 kinase induces phosphorylation of wt p53 at Ser-46 in human MCF-7 breast cancer cells. J Cell Biochem. 2007;100(4):865-74.

30. Beckerman R, Prives C. Transcriptional regulation by p53. Cold Spring Harb Perspect Biol. 2010;2(8):a000935.

31. Lu W, Chen L, Peng Y, Chen J. Activation of p53 by roscovitine-mediated suppression of MDM2 expression. Oncogene. 2001;20(25):3206-16.

32. Brooks CL, Gu W. Ubiquitination, phosphorylation and acetylation: the molecular basis for p53 regulation. Curr Opin Cell Biol. 2003;15(2):164-71.

33. Ljungman M, Paulsen MT. The cyclin-dependent kinase inhibitor roscovitine inhibits RNA synthesis and triggers nuclear accumulation of p53 that is unmodified at Ser15 and Lys382. Mol Pharmacol. 2001;60(4):785-9.

34. Oda K, Arakawa H, Tanaka T, Matsuda K, Tanikawa C, Mori T, et al. p53AIP1, a potential mediator of p53-dependent apoptosis, and its regulation by Ser46-phosphorylated p53. Cell. 2000;102(6):849-62.

35. Phatnani HP, Greenleaf AL. Phosphorylation and functions of the RNA polymerase II CTD. Genes Dev. 2006;20(21):2922-36. 
36. Orphanides G, Reinberg D. A unified theory of gene expression. Cell. 2002; 108(4):439-51.

37. Ramanathan Y, Rajpara SM, Reza SM, Lees E, Shuman S, Mathews MB, et al. Three RNA polymerase II carboxyl-terminal domain kinases display distinct substrate preferences. J Biol Chem. 2001;276(14):10913-20.

38. Ljungman M, O'Hagan HM, Paulsen MT. Induction of ser15 and lys382 modifications of p53 by blockage of transcription elongation. Oncogene. 2001;20(42):5964-71.

39. Sakurikar N, Eastman A. Critical reanalysis of the methods that discriminate the activity of CDK2 from CDK1. Cell Cycle. 2016;15(9):1184-8.

40. Rodríquez Varela MS, Mucci S, Videla Richardson GA, Morris Hanon O, Furmento VA, Miriuka SG, Sevlever GE, Scassa ME, Romorini L. Regulation of cyclin E1 expression in human pluripotent stem cells and derived neural progeny. Cell Cycle. 2018;17(14):1721-1744. https://doi.org/10.1080/153841 01.2018.1496740.

41. McClue SJ, Blake D, Clarke R, Cowan A, Cummings L, Fischer PM, et al. In vitro and in vivo antitumor properties of the cyclin dependent kinase inhibitor CYC202 (R-roscovitine). Int J Cancer. 2002;102(5):463-8.

42. Chen S, Dai Y, Harada H, Dent P, Grant S. MCl-1 down-regulation potentiates ABT-737 lethality by cooperatively inducing Bak activation and Bax translocation. Cancer Res. 2007;67(2):782-91.

43. Chen L, Willis SN, Wei A, Smith BJ, Fletcher Jl, Hinds MG, et al. Differential targeting of prosurvival $\mathrm{BCl}-2$ proteins by their $\mathrm{BH} 3-$ only ligands allows complementary apoptotic function. Mol Cell. 2005;17(3):393-403.

44. Ploner C, Kofler R, Villunger A. Noxa: at the tip of the balance between life and death. Oncogene. 2008:27(Suppl 1):S84-92.

45. Gomes NP, Bjerke G, Llorente B, Szostek SA, Emerson BM, Espinosa JM. Gene-specific requirement for P-TEFb activity and RNA polymerase II phosphorylation within the p53 transcriptional program. Genes Dev. 2006; 20(5):601-12.

46. Ljungman M, Zhang F, Chen F, Rainbow AJ, McKay BC. Inhibition of RNA polymerase II as a trigger for the p53 response. Oncogene. 1999; 18(3):583-92.

47. Gomes NP, Espinosa JM. Differential regulation of p53 target genes: it's (core promoter) elementary. Genes Dev. 2010;24(2):111-4.

48. Wesierska-Gadek J, Gueorguieva M, Horky M. Roscovitine-induced upregulation of p53AIP1 protein precedes the onset of apoptosis in human MCF-7 breast cancer cells. Mol Cancer Ther. 2005;4(1):113-24.

49. Santamaria D, Barriere C, Cerqueira A, Hunt S, Tardy C, Newton K, et al. Cdk1 is sufficient to drive the mammalian cell cycle. Nature. 2007; 448(7155):811-5.

50. Canduri F, Uchoa HB, de Azevedo WF, Jr. Molecular models of cyclindependent kinase 1 complexed with inhibitors. Biochem Biophys Res Commun. 2004:324(2):661-6.

51. Romorini L, Riva DA, Bluguermann C, Videla Richardson GA, Scassa ME, Sevlever GE, et al. Effect of antibiotics against Mycoplasma sp. on human embryonic stem cells undifferentiated status, pluripotency, cell viability and growth. PLoS One. 2013;8(7):e70267.

\section{Publisher's Note}

Springer Nature remains neutral with regard to jurisdictional claims in published maps and institutional affiliations.

Ready to submit your research? Choose BMC and benefit from:

- fast, convenient online submission

- thorough peer review by experienced researchers in your field

- rapid publication on acceptance

- support for research data, including large and complex data types

- gold Open Access which fosters wider collaboration and increased citations

- maximum visibility for your research: over $100 \mathrm{M}$ website views per year

At $\mathrm{BMC}$, research is always in progress.

Learn more biomedcentral.com/submissions 